\title{
ARTHUR DANTO E 0 LIMITE DO PAPEL DO DISCURSO: ENTRE A FILOSOFIA E A LITERATURA
}

\author{
Marcelo Vinicius Miranda Barros ${ }^{1}$
}

RESUMO: Pretende-se avaliar a medida da relação possível entre filosofia e literatura em e a partir do pensador de referência da contemporaneidade, Arthur Danto. Uma vez que ambas buscam discussões de vários significados admissíveis para questões do ser humano, o problema central a que procuramos responder é o de saber se, nessa tentativa, as referidas atividades poderão ou deverão aproximar-se. Tal problema levanta um conjunto de questões que nos propomos pensar a partir de Arthur Danto: pode a literatura, na sua especificidade, acender novas possibilidades de expressão ou intercessão de cogitação filosófica? Ou, mais radicalmente, será sustentável a defesa de Arthur Danto de uma delimitação clara entre filosofia e literatura?

PALAVRAS-CHAVE: Arthur Danto; Filosofia; Literatura; Metáfora; Conteúdo.

ABSTRACT: It is intended to evaluate the measure relation possible between philosophy and literature in and from the reference philosopher of the contemporaneity, Arthur Danto. Once both search solid aspects of discussion of many significant possible for questions of the human being, the 
central problem that we search answer is know if, in this attempt, the relate activities could or should get nearby. This problem brings a set of questions that we propose to think from Arthur Danto: can the literature, in its specificity, open new possibilities of expression or mediation of philosophical reflection? Or, most radically, is it sustainable to defend Arthur Danto to a clear delimitation between philosophy and literature?

KEYWORDS: Arthur Danto; Philosophy; Literature; Metaphor; Content. 


\section{INTRODUÇÃO}

Embora a teoria do filósofo Arthur Danto aborde a arte em geral, pouco discorreu oficialmente e diretamente sobre a literatura (a literatura discutida aqui será, especificamente, de acordo com Danto, os romances, os contos e/ou os poemas). Seu debruçar quase que praticamente nas artes plásticas nos fez sentir, então, a necessidade de direcionar mais o olhar desse filósofo para a literatura, partindo do questionamento feito por ele mesmo, no ensaio Filosofando a literatura da obra $O$ descredenciamento filosófico da arte (2014): literatura é filosofia?

Para Danto, a característica principal da Arte Contemporânea é fazer filosofia da arte, teorizando o próprio conceito de arte. Contudo, "não importa muito se a arte é filosofia em ação ou se a filosofia é arte em pensamento" (DANTO, 2005, p.19).

Deste modo, se tomarmos a literatura como arte, podese dizer então que literatura é filosofia? Considerando uma resposta negativa para esta pergunta, como quer o Arthur Danto, permite-nos interrogá-lo: será sustentável a sua defesa de uma delimitação clara entre filosofia e literatura?

De fato, podemos questionar-nos qual é, então, o papel da filosofia face à literatura, e no período em que a arte tomou consciência da sua natureza filosófica, por que é que Danto faz distinção entre literatura e filosofia?

\section{FILOSOFIA COMO / E / DA LITERATURA}

Antes de entrarmos de fato no cerne da questão deste texto, precisamosconhecer mais a visãode Danto sobre aliteratura, dentro 
do possível, por isso a necessidade de explorarmos também um pouco do ensaio Filosofia como / e / da literatura, da já referida obra.

Danto começa por questionar se a filosofia-comoliteratura possui implicação de que "os textos filosóficos têm ocasionalmente certo grau de mérito literário" (DANTO, 2014, p. 174-175), e coloca esse questionamento como uma posição desconfortável com a qual temos de lidar. O que seria, então, essa posição desconfortável? Danto responde a isso com uma longa citação comparando a Bíblia-como-literatura:

Considere-se a perspectiva comparável da Bíblia-comoliteratura. Certamente ela pode ser lida como tal, sua poesia e sua narrativa encaradas como poesia e narrativa, suas imagens apreciadas por sua força e suas representações morais como um tipo de drama. Mas tratá-la assim é pôr, a uma distância considerável, a Bíblia tida como corpo de revelações, de verdades salvíficas e correções éticas: um texto tal que um pensador como Filo poderia crer que tudo nele - e nada fora dele - é verdadeiro (DANTO, 2005, p.175).

O que filósofo quer dizer nessa citação é que a Bíblia sendo considerada literatura perde a sua força de uma verdade que salva o ser humano (ou a alma humana) e de regras de correções éticas: de como o sujeito deve se comportar diante da vida. Pensá-la como literatura é retirá-la de seu mundo próprio. A Bíblia deixaria de ser uma espécie de Constituição Sagrada (como Lei Fundamental etc.), onde suas leis e regras não teriam tanto valor, afastando-se do princípio de que tudo dentro dela, e somente dentro dela, é verdadeiro, para os 
fiéis. De certo modo, a relação fundamental com a Bíblia se modificaria quando ela recebesse status de literatura. Ou seja:

Meu argumento é somente que há um contraste profundo entre tomar a Bíblia como literatura e vê-la como Palavra, suspeito que classes desconexas de passagens se tornando célebres dependendo de qual ponto de vista assumimos (DANTO, 2014, p. 176).

O que a citação acima vem afirmando é que a Bíblia se tornaria insignificante quando as pretensões de verdades feitas não forem mais incontestáveis. E isso só pode ocorrer se a encararmos como literatura. Analogicamente, à filosofiacomo-literatura é posta contrariamente à filosofia-comoverdade (DANTO, 2014), de modo que, para Danto, a literatura e a filosofia pertencem a mundos diferentes.

O que Arthur Danto procura fazer, com esse exemplo sobre a Bíblia, é preparar um terreno para embasar a sua tese de que a literatura não pode ser filosofia, ou seja, de que se levarmos como metáfora a filosofia, ela deixou há muito tempo de parecer plausíveis como hipóteses estruturais, ao passo que metáfora está na literatura como sendo a "essência". Mas, Danto escreve:

Apenas quis enfatizar que o conceito de verdade filosófica e a forma de expressão filosófica são internamente relacionados o suficiente para que queiramos reconhecer que, quando nos voltamos para outras formas, podemos também estar nos voltando para outras concepções de verdade filosófica (DANTO, 2014, p. 178). 
Encontra-se, agora, uma ressalva, segundo a citação acima, e há uma análise de que se poderíamos pelo menos questionar se aquilo a que cada escritor se propõe pode ser tão facilmente separado das formas aparentemente inevitáveis de se apresentar a obra, de modo que o diálogo aparada em prosa convencional pudesse não ter perdido no processo algo central para esses modos de escrita e seus mundos. Assim, Danto afirma:

A forma como a verdade, tal como eles a entenderam, deve ser compreendida, poderia requerer justamente uma forma de leitura, portanto um tipo de relação com aqueles textos, totalmente diferentes daqueles apropriados para um artigo (DANTO, 2014, p. 178).

Danto, então, se torna aparentemente maleável, em alguns instantes, ao dizer que filósofos com pensamentos realmente novos tiveram que inventar outras formas de expressão:

Mas éigualmente discutível que filósofos com pensamentos realmente novos tiveram simplesmente que inventar novas formas para veiculá-los e que seja possível que, da perspectiva do formato padrão, nenhum caminho por essas outras formas - portanto, nenhum caminho por esses sistemas ou essas estruturas de pensamento - possa ser encontrado (DANTO, 2014, p. 180).

Essa citação nos mostra que se a filosofia é literatura, ela é plena de significado, desde que ela apenas possa mostrar como. Assim: "o modo da filosofia de relacionar a literatura com a realidade pode tornar a filosofia-como-literatura um modo de filosofia-como-verdade" (DANTO, 2014, p. 180). 
Porém, apesar de reconhecer o papel da literatura no decorrer do seu ensaio, Danto procura reafirmar a posição de que o status de literatura à filosofia soa como um problema:

[...] Acredito que os textos filosóficos são mantidos vivos como metáforas quando eles deixaram há muito de parecer plausíveis como hipóteses estruturais, um atributo à sua vivacidade e ao seu poder, ao passo que o seu status enquanto literatura é um prêmio de consolação por não terem sido verdadeiros. Mas isso é desconsiderar exatamente a maneira pela qual a filosofia funciona como funciona a literatura, não no sentido de artefatos verbais extravagantes, mas como um engajamento dos leitores na busca daquele tipo de universalidade que supus caracterizar a referência literária: como se tratasse do leitor no momento da leitura, por meio do processo da leitura. Nós os lemos como literatura nesse sentido porque, no esplêndido pensamento de Hegel, eles existem para o leitor, que está "neles desde o começo" (DANTO, 2014, p. 196).

Seguindo o filósofo, os textos filosóficos implicam na variedade correspondente de tipos possíveis de leitores e, portanto, de teorias daquilo que somos na dimensão da leitura (DANTO, 2014). Contudo, Danto reclama pela impossibilidade da literatura ser filosofia, novamente, ao dizer:

Desse modo, a filosofia é literatura visto que entre suas condições de verdade estão aquelas conexas como ser lido, e então ler aqueles textos supostamente nos revela pelo que somos em virtude de nossa leitura. Entretanto, revela-nos realmente, não metaforicamente, e é por isso que penso que não posso finalmente aquiescer à ideia de que a filosofia é literatura (DANTO, 2014, p. 198). 
Assim, Danto, nessas citações aqui referidas, levanta o seguinte: o problema entre filosofia e literatura está na metáfora como sendo a "essência" da obra, que é característica das artes. Ou seja, quando o escritor Kafka comenta do inseto no seu romance A Metamorfose (1915) é, de certa forma, uma metáfora; já quando a fenomenologia comenta da consciência, a consciência não é uma metáfora, é algo a ser estudado e defendido como tese na sua perspectiva fenomenológica. Em outro modo: uma coisa é um inseto na obra $A$ Metamorfose de Kafka (é uma metáfora), outra coisa é um inseto em uma obra científica de Biologia (não é uma metáfora). Arthur Danto continua ainda apresentando mais argumentações dessa distinção.

\section{FILOSOFANDO A LITERATURA}

Em Filosofando a literatura Arthur Danto é decisivo ao dizer que literatura não é filosofia, assegurando que

Não se pode ter uma visão muito enaltecida da literatura se é um ato de humilhação desconstrutiva assimilar a filosofia a si: quão elevada pode ser nossa visão das mulheres se feminino é um insulto quando aplicado a homens? (DANTO, 2014, p. 206).

Para Danto, é uma degradação a filosofia ser comparada à literatura, e a literatura não pode se enaltecer, já que ela é usada para criar um status de humilhação à filosofia. $\mathrm{O}$ autor ainda nos diz que se a filosofia é comparada à literatura, a filosofia deveria examinar a si mesma para saber se de fato ela tem um status de literatura: 
Bem, se a filosofia é tão próxima da literatura a ponto de serem tratadas como uma só coisa [...] Ela poderia começar a readquirir a dignidade que procura à custa da literatura ao empreender a redignificação da própria literatura. E então ela pode examinar a si mesma para ver se de fato tem a dignidade que encontra na arte. Minha opinião sobre essa questão é que ela não tem essa dignidade, mas uma dignidade própria, que só pode ser reivindicada distinguindo-a da arte. $\mathrm{O}$ filósofo da arte hoje tem a tarefa de um duplo recredenciamento, sendo que um deles é a condição para o outro (DANTO, 2014, p. 206-207).

Assim, o filósofo afirma novamente que não podemos levar em frente a ideia de que literatura é filosofia, pois a filosofia não tem essa dignidade, mas uma dignidade própria, que só pode ser reivindicada distinguindo-a da arte, e que o filósofo da arte tem um papel fundamental também para o seio da filosofia em geral, já que:

o destino de sua própria identidade deva ser enlaçado com o que os filósofos, caracteristicamente, no seu desprezo pela arte, deveriam ter descartado como ramo mais periférico, quase frívolo, da filosofia. Em minha visão, a filosofia da arte é o coração da filosofia (DANTO, 2014, p. 207).

Não é só levantada a importância da filosofia da arte no seio da filosofia como um todo, mas também argumenta mais diretamente a favor de sua tese que diz que literatura não é filosofia. Portanto, ele cita, como exemplo, o romance A Náusea (1938), do filósofo Sartre:

A Náusea, um romance escrito por um filósofo [...] Contém pensamentos filosóficos, mas conter pensamentos 
filosóficos não torna algo em texto filosófico - do contrário, certos biscoitos da sorte que cruzaram meu caminho se qualificariam a tanto [...] A Náusea não é um texto filosófico [...] E estou convencido de que o que torna uma obra filosófica não é uma questão de freqüência de pensamentos filosóficos. Um dicionário de citações filosóficas conteria mais desses pensamentos do que a Metafísica de Aristóteles (DANTO, 2014, p. 210).

Danto deixa claro que conter pensamentos filosóficos não faz um determinado romance ser realmente filosofia. A Náusea foi um exemplo de Danto, mas poderíamos usar quaisquer outros exemplos, como os romances ou as novelas do filósofo Albert Camus ou irmos ao extremo: usarmos obras de escritores que não são considerados filósofos formalmente, como é o caso de Dostoiévski, e, ainda, o estilo de escrita do romance Assim falou Zaratustra (1883), escrito pelo filósofo Nietzsche.

$\mathrm{Na}$ verdade, existem inúmeros romances, de autoria de filósofos e não filósofos, que são atingidos por essa citação de Danto, pois ele praticamente cria uma espécie de "fórmula" com essa sua afirmação, para sustentar a sua argumentação de que literatura não pode ser filosofia. Mas, não se conclui essa afirmação somente nessa citação, já que esse filósofo também problematiza se um determinado romance de fato "incorpora" a ideia que a filosofia de um determinado escritor requer:

É claro que a incorporação não é a única ideia filosófica, mas pelo menos podemos dizer o que um romance deve fazer para que seja, além de literatura, uma obra de literatura filosófica: ele deve incorporar uma ideia filosófica. Cada obra desse tipo teria de ser, de algum modo, uma metáfora para si mesma (DANTO, 2014, p. 218). 
Danto de modo algum está se contradizendo, mesmo que em um dado momento afirme que um romance ao conter pensamentos filosóficosnãofazdesseromanceumtexto filosóficoeemoutrodado momento afirme também que para um romance se tornar filosofia é preciso que ele incorpore uma ideia filosófica. Na há contradição de afirmações, porque a arte passa a fazer filosofia quando tem a tomada da consciência da natureza filosófica da arte e a coloca em questão, como bem fez o artista Andy Warhol, segundo Danto.

Assim, a obra literária só seria filosofia também se ela passasse a questionar a natureza da própria literatura e não porque a obra literária contém pensamentos filosóficos. Por isso não podemos afirmar, nesse quesito, que ele entra em contradição:

Há romances que buscam incorporar a ideia do romance e, se essa é a ideia da incorporação, então esses romances incorporam essa ideia; mas essa é uma classe especial de obras altamente autorreflexivas, hoje encontradas com muito mais freqüência do que no tempo de Eliot (DANTO, 2014, p. 218).

O filósofo nos diz que há romances filosóficos, porque são romances que incorporam a ideia de questionar sobre a natureza do romance. Da mesma forma que a arte, sendo filosofia, se pergunta: $\mathrm{O}$ que é arte? E literatura também é arte, para Danto. Portanto, será que, para Danto, muitos dos romances de James Joyce são literaturas filosóficas, da mesma forma que as obras de Andy Warhol são artes filosóficas? Joyce pode ser considerado autor de obras literárias filosóficas ao considerarmos que ele "quebra" com os modelos "canônicos" da literatura? Assim, temos o Finnegans Wake, de Joyce, que abandonou todas as convenções de construção de enredo e 
personagem e é escrito numa linguagem peculiar, de modo a questionarmos se não se trata de uma literatura como filosofia. Dando continuidade a essa lógica de Danto, será também que a vanguarda da poesia concreta é filosofia? E o que dizer do poema-processo de Wlademir Dias-Pino, é uma arte filosófica?

Contudo, não é nosso papel analisar a obra de Joyce, a de Wlademir e nem a poesia concreta, mas deixar explícito se a obra desses escritores e esse tipo de poesia vanguardista podem ser encarados como literatura filosófica, segundo a visão de Danto. Por isso a preocupação de Danto em separar literatura da literatura filosófica ao dizer que

Se a literatura é a incorporação de idéias, todo texto filosófico seria, então, literatura, e eu acho que isso é muito grosseiro; e poderia obscurecer o limite entre exemplificação e incorporação, cuja separação deve ser um imperativo para uma filosofia da literatura (DANTO, 2014, p. 219).

Então, segundo Danto, se pode ter filosofia literária, partindo do ponto que devemos tomar cuidado para não generalizar toda a literatura como filosófica, parece que chegamos à ideia de que existe literatura como filosofia, contudo nem toda literatura é filosofia. Se, para Danto, a arte contemporânea faz filosofia da arte e não somente arte, a literatura, sendo também uma arte, faz dela mesma igualmente filosofia da arte. Caso contrário, Danto entraria em contradição, o que não é plausível devido ao que analisamos aqui sobre a possível contradição nas afirmações do filósofo e que concluímos não encontrar tal incoerência. 
Portanto, se para Danto a filosofia só pode ser percebida como literatura se a literatura for percebida como objeto questionador da natureza literária, a questão que colocamos é se podemos ver a literatura como filosofia ao conter pensamentos filosóficos, e não somente quando a literatura questiona a sua própria "essência"?

\section{LIMITE DO PAPEL DO DISCURSO ENTRE A FILOSOFIA E A LITERATURA}

A questão que colocamos é se podemos ver a literatura como filosofia ao conter pensamentos filosóficos e não somente quando a literatura questiona a sua própria "essência", como quer Danto. Assim, o primeiro argumento desse filósofo é que a literatura não pode ser filosofia devido à metáfora, como foi discutido neste texto.

Mas, diferente da discussão do conceito de arte, parece que Danto observou um conceito de filosofia que não é o contemporâneo. O que é preciso salientar é que o aparecimento de filosofias que assumiram como serviço não mais explicar o mundo a partir de certos pressupostos metafísicos inteiramente abstratos e sim "formular uma experiência do mundo", um contato com o mundo que precede todo "pensamento sobre o mundo", contribuiu para que "a tarefa da literatura e da filosofia já não possam andar separadas" (MERLEAU-PONTY, 1948, p. 28). Alguns exemplos dessas filosofias são a fenomenologia e os diversos existencialismos e até a filosofia do absurdo de Albert Camus. Salientando, ainda, a filosofia de Foucault, o qual acreditava que a literatura trazia em seu interior a possibilidade de estabelecer novas formas de pensamento (MACHADO, 2000).

Segundo Merleau-Ponty, quando alguém está interessado em dar voz à experiência do mundo e mostrando como a 
consciência escapa para o mundo, não se pode mais se creditar com a realização de uma transparência perfeita de expressão. $\mathrm{E}$ a expressão filosófica assume as mesmas ambigüidades como a expressão literária, se o mundo é tal que ele não pode ser expresso exceto em "histórias":

A tarefa da literatura e da filosofia já não podem andar separadas. Quando se trata de dar voz à experiência do mundo e de mostrar como a consciência escapa pelo mundo, uma já não pode deixar de conseguir uma transparência perfeita de expressão. A expressão filosófica assume as mesmas ambigüidades que a expressão literária, posto que o mundo está feito de tal modo que não pode ser expressado, senão através de histórias mostrado como que com o dedo (MERLEAU-PONTY, 1964a, p. 28). ${ }^{2}$

Merleau-Ponty, assim como vários filósofos contemporâneos, propõe-se elaborar uma filosofia concreta, enraizada no corpo e no mundo, que seja expressão ou metamorfose da própria vida. Assim, o fato é que

A filosofia será, então, um percurso aberto e inacabado, em contínua transformação e renovação, uma "interrogação continuada", tornando-se o filósofo um "perpétuo principiante". Esta filosofia é gizada num confronto crítico com a "filosofia clássica" abstracta, que se cinde da vida (DIAS, 1997, p.30).

A filosofia, segundo Dias, não é um saber autônomo e fechado, assim, o que se percebe é que a filosofia contemporânea (e o conceito desta filosofia se opõe até mesmo a Descartes e ao cartesianismo) se diferencia da filosofia tradicional ou "filosofia 
clássica" (DIAS, 1997) e por isso impõe uma pergunta: a filosofia que Danto considerava em seu momento não é de viés quase tradicional, mesmo ele olhando para arte contemporânea?

Acompanhando, por enquanto, Merleau-Ponty, "ao longo da sua obra o fenomenólogo francês procura superar uma filosofia da consciência e do sujeito, da posse ou da dominação da realidade" (DIAS, 1997, p.31). Essa superação do domínio da realidade parece contrariar a visão da filosofia de Danto sobre a metáfora, pois nada é real, tudo é metafórico. Uma filosofia que domina a realidade, que Danto procurou afirmar ao utilizar a Bíblia-comoliteratura, para mostrar que a metáfora não é válida no campo da filosofia, é vista por diversos filósofos contemporâneos, como Merleau-Ponty, Albert Camus e Nietzsche, como um problema. Ou seja, Danto, antes de usar o argumento da metáfora para desqualificar a literatura como filosofia, tinha uma grande batalha a realizar com os filósofos contemporâneos sobre a importância da própria metáfora no âmbito da filosofia (Merleau-Ponty comenta de uma ontologia literária e não de uma metáfora de fato, mas mesmo assim válida aqui e veremos o porquê).

E nem precisaria exemplificar filósofos como Merleau-Ponty, pois filósofos anteriores, como Nietzsche, já seria um início do desafio para Danto debater sobre a própria questão da metáfora e ir até aos pensadores de hoje, para depois, se possível, assumir a metáfora como uma premissa de desqualificação filosófica.

Mesmo Danto considerando a existência de Nietzsche, parece esquecer que este foi quem teria, provavelmente, percebido de forma aguda a crise da metafísica a ponto de pensar não somente se a filosofia seria arte, como ainda a importância da metáfora na própria filosofia e seus conceitos. Diz o filósofo alemão: 
"no filósofo, a atividade continua sob a forma de metáforas" (NIETZSCHE, 1872, p. 90). O que Nietzsche questiona é que mesmo a filosofia vive da metáfora. "Tempo, espaço e causalidade são apenas metáforas do conhecimento, por meio das quais interpretamos as coisas" (NIETZSCHE, 1872, p. 140).

Nietzsche afirma que a palavra não é feita para a abstração, para a filosofia, como parece pensar Danto ao se assemelhar, de certa forma, aos filósofos mais tradicionais e ao usar a analogia da Bíblia-como-literatura e encerrando-a à um mito restrito. Ou seja:

Dessas intuições, não há nenhum caminho regular que vá dar ao país dos esquemas fantomáticos, das abstrações: a palavra não é feita para elas, o homem se torna mudo quando as vê, ou então só fala por meio de metáforas proibidas e por meio de ajuntamentos conceituais inéditos para responder de maneira criadora, pelo menos por meio da destruição e da derisão das antigas barreiras conceituais, com a impressão da poderosa intuição do presente (NIETZSCHE, 1872, p. 2).

Nietzsche desconstrói a ideia da realidade, a ponto da filosofia atuar metaforicamente. E, segundo Nietzsche, quem pensa ao contrário dessa firmação é frio a ponto de não perceber a sutileza dessa sua declaração:

Quem estiver impregnado dessa frieza dificilmente acreditará que o conceito, posto a nu e octogonal como um dado e, como este, amovível, não é outra coisa senão o resíduo de uma metáfora, e que a ilusão da transposição artística de uma excitação nervosa em imagens, se não é a mãe, é, contudo, a avó de todo conceito (NIETZSCHE, 1872, p. 1). 
Mas, não se tem o objetivo de destrinchar cada pensador aqui e sim mostrar que ao querer usar a metáfora como premissa válida de fator distintivo entre a literatura e a filosofia, Danto levanta um problema muito mais complexo que tem de enfrentar a ponto de ser cedo demais e muito simplista em usar a metáfora como um critério a respeito da filosofia e literatura.

O que se quer afirmar com isso é que, neste contexto, a filosofia não pode ser um saber já feito ou constituído, uma ordenação de conceitos previamente elaborados, exigindo antes uma contínua transformação da lógica e do vocabulário já fundados. Ou seja:

[...] se a filosofia pode falar, é porque a linguagem não é apenas o reservatório de significações fixadas e adquiridas, mas porque o seu próprio poder cumulativo resulta de um poder de antecipação ou de pré-possessão, porque não se fala apenas do que se sabe [...], mas também do que não se sabe, para sabê-lo. A linguagem, ao fazer-se, exprime, pelo menos lateralmente, uma ontogénese de que ela faz parte (MERLEAU-PONTY, 1964b, p. 139).

Tal é o problema da constituição ou instituição da linguagem e que Danto precisava considerar delicadamente ao se referir à metáfora como um descredenciamento de uma literatura como filosofia, já que, como disse Merleau-Ponty, não se fala apenas do que se sabe, mas também do que não se sabe, para sabê-lo. Assim ao questionarmos se a literatura é filosofia, aos olhos da filosofia tradicional, ela não pode ser, mas, aos olhos de diversas filosofias contemporâneas (e até da filosofia antiga, se utilizando do "Mito da caverna" e "Diálogo socrático", por exemplo), é possível ser. Se usarmos as teorias com suas 
idéias absolutas e universais, tendo como referência a filosofia tradicional, elas, ao invés de contribuírem para dar razões ao que se passa nos romances, acabam obscurecendo a compreensão que o narrador pode ter daquilo que está acontecendo.

$\mathrm{E}$ isso acontece porque a teoria de uma filosofia tradicional coloca as suas idéias antes da ação, do fato, do processo que fazem essas idéias surgirem, sendo insuficiente dar conta da literatura como filosofia. Portanto, inserir uma teoria antes de uma narrativa, faz da literatura uma representação de idéias e não um sistema que gera tal teoria. Mas, hoje, a filosofia é compreendida ainda como uma filosofia da ação ou do ato. Não é a toa que Sartre, por exemplo, se remete sempre aos exemplos, aos fatos, às histórias, às práticas e as narrações literárias. A ação aparece como o primeiro princípio do existencialismo, a partir da qual as demais noções se sobrepõem. Estamos mergulhados num mundo que não cessa de colocar novas questões para a filosofia.

Ora, a reestruturação do homem e da existência é um processo quedemandaohomem em movimento, essehomemexistindopara, possivelmente, ser. Dessa forma, perceberam os existencialistas que a reafirmação dos valores da existência é possível unicamente na vida, mediante o retrato vivo do existir, possível na arte literária.

Assim, temos os romances, como os de Sartre, mostrando o momento em que a literatura abandonou suas tradicionais fórmulas de expressar o homem, analisando simplesmente o que ele é, ou como ele é, para interrogar o porquê e o para quê, ela deixou de ser unicamente uma arte de deleite, de contar histórias, para ser uma arte filosófica que se propõe não somente explicar o universo e descobrir suas condições e possibilidades, como ainda formular uma experiência do mundo, um contato com o cosmos e com os seres humanos ontologicamente diferenciados e inseridos no complexo dos problemas da existência. 
E isso é considerar uma filosofia como metafórica, como afirma Nietzsche. Destacando, então, a importância da filosofia que não se resume a conceitos ou ao "falar apenas do que se sabe", como disse Merleau-Ponty, e que Danto pareceu não se preocupar ao se referir à metáfora como um argumento fechado. É preciso perceber, então, que na filosofia contemporânea há questões que nos fazem interrogar sobre os limites do papel do discurso na filosofia e na literatura. Assim, o problema entre filosofia e literatura está na metáfora? Levantar uma argumentação dessas relaciona diversas implicações filosóficas, impedindo de se chegar a uma conclusão tão segura como Danto acreditava poder realizar na sua afirmação de critério de distinção. Segundo Merleau-Ponty,

A fecundidade da linguagem reside nesta sua contínua ontogénese, o que exige um rompimento com a linguagem e pensamento já feitos, com o mundo autônomo de significações unívocas ou de enunciados completos e acabados, e promove uma incessante inovação (DIAS, 1997, p. 36).

Neste contexto, a filosofia não poderá ser uma obra feita ou acabada de uma vez por todas, pois está sempre em gestação, é incoativa, podendo dizer-se da obra filosófica o que dizia Baudelaire da pintura de Corot: "Uma obra feita não é necessariamente acabada nem uma obra acabada é necessariamente feita” (BAUDELAIRE, 1964, p. 61).

Mas, parece que Danto também reconhecia a ideia de que a filosofianãopoderáser uma obrafeita ouacabada, seconsiderarmos sua citação posto anteriormente neste texto, em que diz que a forma 
como uma verdade é compreendida exigiria relações de textos diferentes daqueles apropriados para um artigo (DANTO, 2014).

Danto se torna aparentemente consciente desse fato, ao dizer que filósofos com pensamentos realmente novos tiveram que inventar outras formas de expressão. Isso pode ser o caso dos filósofos mais contemporâneos e as suas literaturas, como os citados aqui. Contudo, é sabido como é o conceito de filosofia como arte, para Danto: aquela arte que questiona a natureza da arte e não aquela que contém conteúdos filosóficos, e é esta que finca todo o problema discutido aqui.

Só que, como visto, não se escreve para dizer o que já se sabe ou concebeu, mas para descobrir. A irredutibilidade da literatura a uma ideia ou levar o status de metáfora para a literatura não é assim uma fraqueza, como quer Danto, mas antes a expressão da sua força e espessura:

O prodígio da obra literária reside na ousadia e exploração da sua "linguagem conquistadora", na criação de uma palavra que tem sempre a frescura da novidade, do que se diz pela primeira vez, e ainda o carácter de urgência e de tensão próprios do irrepetível (DIAS, 1997, p. 37).

Essa afirmação desconstrói também a visão de Danto que ao colocar o status de literatura à filosofia seria uma espécie de retirá-la de seu mundo próprio, já que é uma degradação para a filosofia quando é comparada a literatura. Mas, será que devido ao que foi argumentado até a este momento nos permite ainda aceitar essa visão de Danto? Tudo indica que não. Como diz Merleau-Ponty, a literatura é um "poder de metáfora continuada" (MERLEAU-PONTY, 1996, p. 219). 
A radicalidade da literatura e de toda a arte, como da própria filosofia, reside para o autor numa "abertura às coisas sem conceito", na "apresentação sem conceito do Ser universal" (MERLEAU-PONTY, 1964) que nos abre ao desconhecido em vez de confirmar aquilo que já conhecemos:

A radicalidade significa assim acon-ceptualidade, o que não deve interpretar-se como uma orientação para o irracional e o inconceptual, mas antes como uma exigência de alargamento e aprofundamento da racionalidade, a busca de uma racionalidade mais funda e integradora que não esconjure a própria dimensão mágica e onírica (DIAS, 1997, p. 38).

É percebido que a metáfora já não possa ser um critério de invalidação filosófica para literatura e nem um status de humilhação para a filosofia, já que, superficialmente expondo, a metáfora ainda pode ter um conceito muito mais amplo na filosofia, pois não se fala apenas do que se sabe, mas também do que não se sabe, para sabê-lo ou a necessária "abertura às coisas sem conceito", como assegura MerleauPonty; ou a metáfora artística se não é a mãe, é, contudo, a avó de todo conceito e a literatura é uma força de explorações conceituais inéditos, como afirma Nietzsche. Além disso, tanto a filosofia como a literatura precisa de uma "linguagem extra", se pretendem mostrar algo de novo no conhecimento.

Aanálisesobreametáforacomojuízocríticotomoumuitotempo e exigiu uma capacidade de síntese que fez este texto deixar muitas questões de fora, mas que contemplou a ideia central: o perigo de seguir a visão de Danto de que a metáfora pode ser um critério para que a literatura não obtenha o status de filosofia, pois isso encontra muitos problemas filosóficos que precisa ser resolvidos antes. 
Outra questão que implica a literatura como filosofia é a citação de Danto, posto anteriormente neste texto, sobre $A$ Náusea, de Sartre. Aqui encontramos um dos pontos importante do texto de Danto. Nessa citação, usando exemplos como biscoito da sorte e dicionário de citações de pensamentos filosóficos, ele deixa claro que conter pensamentos filosóficos não faz um determinado romance ser realmente filosofia.

Mas, não seria essa analogia do dicionário de citações de pensamentos filosóficos, feito por Danto, um tanto exagerada? E mais: a analogia de certos biscoitos da sorte não tem as suas citações fora de contexto, perdendo sua "tese"? Pois os pensamentos filosóficos no biscoito da sorte ou no dicionário de citações filosóficas não têm um contexto e um embate de idéias como se tem em certos romances, como A Náusea, de Sartre.

Outro exemplo são os romances de Dostoiévski. Estudiosos como Bakhtin têm caracterizado o trabalho de Dostoiévski como diferente de outros romancistas; ele parece não almejar por uma visão exclusiva e vai além da descrição em distintos ângulos, caracterizando-o como romance polifônico. Dostoiévski instituiu romances com uma força dramática em que os opostos pontos de vista são alcançados em intensa dinâmica entre os personagens. Esse escritor criou um trabalho envolvido em diálogos socráticos apaixonados (diálogo socrático consiste em uma técnica de investigação filosófica feita em diálogo) a busca de Deus, da moral e do sofrimento dos inocentes (BAKHTIN, 1986):

Ao tomarmos conhecimento da vasta literatura sobre Dostoiévski, temos a impressão de tratar-se não de um autor que escrevia romances e novelas, mas de vários autores e pensadores que representam toda uma série de discursos e teorias filosóficas (BAKHTIN, 1986, p. 13) 
A citação de Bakhtin afirma que ao tomarmos conhecimento da vasta literatura de Dostoiévski, temos a impressão de tratarse não de um autor ou artista, que escrevia romances, mas de toda uma série de discursos filosóficos de vários autores e pensadores. Ou seja, Danto esquece que romances como $A$ Náusea, de Sartre, as obras de Dostoiévski etc. vão além de conter pensamentos filosóficos, como os biscoitos da sorte, pois há sim um embate de idéias, como no caso de Dostoiévski, que ocorre entre o materialismo, o niilismo, a política e a religião, em uma violenta dinâmica que é presa em seus personagens como uma espécie de tese, onde cada personagem defende a sua.

Será que Danto se prendeu demais às citações de pensamentos filosóficos em si e esqueceu o contexto e a dinâmica de como elas estão inseridas e se manifestam embasadamente numa obra literária, numa espécie de método socrático? Não podem essas obras literárias ser comparadas a meros biscoitos da sorte, já que nestes são simplesmente colocados tais pensamentos sem contexto, sem embasamento, pois a ideia ali, no biscoito da sorte, é diferente de certos romances, principalmente os romances citados pelo próprio Danto, que não se resumem à simples citações filosóficas. Inclusive Sartre realizava também debates filosóficos com Albert Camus e vice-versa através de seus escritos dramatúrgicos e romanescos. E lembrando que a filosofia não é um saber fechado, insistiremos na arbitrariedade da antiga oposição entre Arte e Filosofia e que Albert Camus afirmou que:

A única argumentação aceitável residia na contradição entre o filósofo encerrado no meio do seu sistema e o artista diante da sua obra. Mas isto era válido para uma certa forma de arte e de filosofia que aqui consideramos secundária (CAMUS, 2004, p. 112). 
Então, ao dizer que o autor, mesmo sendo um filósofo, ao escrever um romance com pensamentos filosóficos não faz de sua obra filosófica é negar que a ideia de uma arte separada do seu criador não está só fora de moda, como é falsa (CAMUS, 2004). E "em oposição ao artista, afirma-se que nenhum filósofo jamais criou vários sistemas. Mas isto é verdade na medida em que nenhum artista expressou mais que uma única coisa sobe diversas facetas" (CAMUS, 2004, p. 112).

Camus afirma que o artista, tanto quanto o filósofo, compromete-se com sua obra e se transforma dentro dela, ou seja, "não há fronteiras entre as disciplinas que o homem emprega para compreender [...] Elas se interpenetram e a mesma angústia as confundem" (CAMUS, 2004, p. 112).

A arte, para Camus, cobre com imagens o que carece de razão. A arte procura dar conta, então, como dito por MerleauPonty, de uma "abertura às coisas sem conceito". "Se o mundo fosse claro, não existiria arte" (CAMUS, 2004, p. 114). E isso é também o papel da filosofia contemporânea: só pensamos forçados, impulsionados por algo que está fora do pensamento, algo ainda não pensado, não pensável. É aí que vale a pena pensar, é aí que o pensamento filosófico é forçado a criar conceitos.

Se Danto afirmou que literatura, como $A$ Náusea, não é uma obra filosófica, isso só deve ser válido, segundo Camus,

nos tempos em que era fácil separar a filosofia do seu autor. Hoje, quando o pensamento não aspira ao universal, quando a sua melhor história seria a dos seus arrependimentos, sabemos que o sistema, quando é válido, não se separa de seu autor. A própria Ética, num dos seus aspectos, é apenas uma longa e rigorosa confidência (CAMUS, 2004, p. 115). 
O que Camus afirma é que o pensamento abstrato obtém por fim seu suporte de carne, o ser humano. E, ao mesmo tempo, os jogos romanescos (os romances literários) do corpo e das paixões se ordenam um pouco mais, seguindo as exigências de uma visão de mundo (CAMUS, 2004). Ou seja, tal pensamento de Danto era válido nos tempos em que era fácil separar a filosofia do seu autor, mas hoje "os grandes romancistas são romancistas filosóficos, ou seja, o contrário de escritores com teses. Vejam Balzac, Melville, Stendhal, Dostoiévski, Proust, Malraux, Kafka, para citar só alguns" (CAMUS, 2004, p. 116). Aqui Camus afirma que grandes escritores eram filósofos e faziam da sua literatura uma filosofia.

Danto via a literatura como filosofia, caso a literatura se questionasse; já Camus via literatura como filosofia se a literatura tivesse conteúdos de pensamentos filosóficos quando válidos, ou seja, conteúdos com uma consistência interna do argumento, mas uma afirmação de Camus faz nos lembrar de uma afirmação de Danto, com as devidas ressalvas:

Mas, justamente, a opção que fizeram de escrever com imagens mais que com raciocínios revela um certo pensamento que lhes é comum, persuadido da inutilidade de todo princípio de explicação e convencido da mensagem instrutiva da aparência sensível (CAMUS, 2004, p. 116).

Camus considera a obra literária como um fim e ao mesmo tempo como um princípio. É o filósofo que, com seu pensamento inovador, é persuadidoa escrever uma obraliterária e nãoum ensaio filosófico, por acreditar que aquela assegura mais a sua filosofia inovadora do que este. E Danto parece, como vimos, confirmar essa argumentação de Camus, ao dizer que a forma padrão pode 
não dar conta de um novo pensamento filosófico, exigindo outro formato, formato este que tanto o filósofo Albert Camus utilizou com bastante força na sua filosofia: o formato literário.

Mas o problema aqui, já que parecem terem a mesma visão, é que Danto não vê filosofia na literatura exceto se for um autoquestionamento de sua própria natureza, o que é obviamente contrário a Camus, que fazia da literatura sua expressão filosófica. E, como dito por Camus: por ser incapaz de sublimar o real, o pensamento se limita a imitá-lo e o romance é o instrumento desse conhecimento.

Se Danto usou como exemplo a obra do escritor Sartre, Camus também usa como exemplo outro escritor, o Dostoiévski:

Todos os heróis de Dostoiévski se questionam sobre o sentido da vida. Nisto são modernos: não temem o ridículo. O que distingue a sensibilidade moderna da sensibilidade clássica é que esta se nutre de problemas morais e aquela de problemas metafísicos. Nos romances de Dostoiévski, a questão é colocada com tal intensidade que só admite soluções extremas. A existência é enganosa ou é eterna. Se Dostoiévski se contentasse com essa análise, seria filósofo. Mas ele ilustra as conseqüências que esses jogos do espírito podem ter na vida de um homem e por isso é um artista (CAMUS, 2004, p. 119).

É fato que essa citação de Camus vai de contra as duas visões de Danto, que são: conter pensamentos filosóficos não faz da literatura uma literatura-filosófica e o status de literatura retira a filosofia do seu mundo, pois Camus afirma que nos romances de Dostoiévski são colocados pensamentos filosóficos de forma tão extrema que se Dostoiévski se contentasse com a análise desses 
pensamentos, seria um filósofo, ou seja, Dostoiévski pode ser um filósofo, mas ele está além de um filósofo, e isso encontramos traduzido, para Camus, na própria forma do discurso literário de suas obras. E quando Camus diz que Dostoiévski seria um filósofo caso se contentasse com a análise desses pensamentos em sua obra, mas ao ilustrar as conseqüências que esses jogos do espírito podem ter na vida de um homem, é um artista, afirma que o contentamento é pouco e fica para os filósofos. Parece que Camus quase que inverte a lógica de Danto no que tange ao status de literatura e nos força a perguntar: qual o status é humilhante, o de literatura ou o de filosofia? Ou nenhum deles?

Camus também contraria diretamente a visão de Danto com a firmação: "Um romance nunca passa de uma filosofia posta em imagens.Emumbomromance, todaafilosofiapassoupelasimagens" (CAMUS, 1998, p. 133). Oque ele quer dizeréque uma obraliterária duradoura não pode deixar de lado o pensamento profundo, a saber, a filosofia. O próprio Camus é um exemplo disso, com as suas obras literárias que debatiam com outros grandes filósofos.

Desfazendo mais uma vez a analogia de Danto de que literatura com pensamentos filosóficos não passa de biscoitos da sorte, ignorando, como dito anteriormente aqui, o contexto e toda dialética onde estão inseridos tais pensamentos na literatura, Camus diz que "está fusão secreta da experiência com o pensamento, da vida com a reflexão sobre seu sentido, é o que faz o grande romancista" (CAMUS, 1998, p. 133). Ou seja, mais uma vez é enfatizado, agora com fundamentos de Camus, que conteúdos de pensamentos filosóficos na literatura não podem ser comparados a meros biscoitos da sorte, pois eles não estão soltos, mas sim dentro de um sistema complexo. 
O que vimos ligeiramente com Merleau-Ponty, Nietzsche, Bakhtin e, agora, com mais ênfase, com Camus, mesmo cada um com a sua perspectiva, é que "trata-se hoje de um romance em que este equilíbrio é rompido, em que a teoria prejudica a vida. Tal coisa é bastante comum há algum tempo" (CAMUS, 1998, p. 133).

Parece que mesmo Danto reconhecendo a dinâmica da arte contemporânea, se esqueceu da dinâmica da filosofia contemporânea. Mesmo ele fazendo filosofia da arte, pareceu não perceber que, como a história da arte, a da filosofia também muda.

Camus ainda afirmou: "O filósofo, mesmo que seja Kant, é criador. Tem seus personagens, seus símbolos e sua ação secreta. Tem seus desenlaces" (CAMUS, 2004, p. 115). Assim, da vinculação da filosofia com a literatura, o que nasce são conceitos, personagens conceituais que operam no plano de imanência, ou de consistência, da filosofia. Ou seja, ao se encontrar com a literatura, a filosofia tem como efeito produzir diferenciações múltiplas no pensamento, resultando na criação de conceitos filosóficos e não de modelos analíticos, teóricos, a serem reaplicados ao objeto artístico ou ao texto literário.

A filosofia contemporânea, como vista aqui, trata-se do projeto de uma filosofia que sirva para pensar a vida, que só funcione uma vez acoplada a outros campos de experimentação que a forçam a criar, a saber: a literatura. E é assim que a filosofia de hoje, como lugar de criar conceitos, se força a cruzar com outros personagens, que são aqueles também da literatura filosófica.

Considerandocertasfilosofiascontemporâneas, especialmente a fenomenologia, "a filosofia não é o reflexo de uma verdade prévia, mas, assim como a arte, é a realização de uma verdade" (MERLEAU-PONTY, 1999, p. 19). Merleau-Ponty afirma, então, que o que a filosofia diz, as suas significações, não são o invisível 
absoluto e assim “a verdadeira filosofia é reaprender a ver o mundo, e nesse sentido uma história narrada pode significar o mundo com tanta 'profundidade' quanto um tratado de filosofia" (MERLEAU-PONTY, 1999, p. 19), ou seja, a filosofia e a literatura "interrogam o estatuto das ideias e perseguem um pensamento sensível, ambas desenvolvem uma permanente reflexão estéticofilosófica" (DIAS, 1997, 43).

Mas, se Camus reconhece, em uma afirmação sua, que Dostoiévski está além de um filósofo, Danto, por sua vez, disse em uma entrevista que: "leio Proust o tempo todo, e Henry James também, por causa da estupenda visão deles. Eles são mais sábios do que os filósofos" $"$.

\section{NOTAS}

${ }^{1}$ Graduando em Psicologia pela Universidade Estadual de Feira de Santana (UEFS). Integrante do Grupo de Estudos em Filosofia da Arte de Arthur Danto e do Grupo de Pesquisa em Filosofia Francesa Contemporânea (GESTUFFRANCO) no NEF/UEFS. Coordenou projetos acadêmicos sobre os escritores Kafka e Dostoiévski. Endereço eletrônico: marcelovmb@gmail. com

${ }^{2}$ From now on the tasks of literature and philosophy can no longer be separated. When one is concerned with giving voice to the experience of the world and showing how consciousness escapes into the world, one can no longer credit oneself with attaining a perfect transparence of expression. Philosophical expression assumes the same ambiguities as literary expression, if the world is such that it cannot be expressed except in "stories" and, as it were, pointed at. (MERLEAU-PONTY, 1964a, p. 28).

${ }^{3}$ Cuando uno empieza a estudiar la abundante literatura crítica acerca de 
Dostoievski, da la impresión de que se trata no de un autor que escribió novelas y cuentos, sino de autores y pensadores varios que plantean un conjunto de exposiciones filosóficas (BAJTÍN, 1986, p. 13).

${ }^{4}$ Entrevista do Filósofo e Crítico de Arte do The Nation, Arthur Danto ao filósofo Paulo Ghiraldelli Jr.(uma versão resumida foi publicada na Folha de S. Paulo). A publicação dessa conversa foi permita pelo prof. Danto, com direito do Centro de Estudos em Filosofia Americana (CEFA) e Portal Brasileiro da Filosofia. 


\section{REFERÊNCIAS}

BAJTÍN, M. Problemas de la Poética de Dostoievski. Tradução Tatiana Bubnova. México: Fondo de Cultura Económica, 1986, p. 13.

BAUDELAIRE, C. L'Art Romantique. Tradução Ernest Raynaud. Paris, Garnier, 1962.

CAMUS, A. A Inteligência e o Cadafalso. Tradução Manuel da Costa Pinto. São Paulo: Record, 1998.

CAMUS, A. O Mito de Sísifo. Tradução: Paulina Wacht. São Paulo: Record, 2004.

DANTO, A. A transfiguração do lugar comum: uma filosofia da arte. Tradução Vera Pereira. São Paulo: Cosac Naify, 2005.

DANTO, A. O descredenciamento filosófico da arte. Tradução Rodrigo Duarte. Belo Horizonte: Autêntica, 2014.

DIAS, M, I. Vestígio do Mundo. Literatura e filosofia em MerleauPonty. Philosophica 10, Universidade de Lisboa, Lisboa, 1997, pp. 29-44,.

MACHADO. R. Foucault, a filosofia e a literatura. Tradução Roberto Machado. Rio de Janeiro: Zahar, 2000.

MERLEAU-PONTY, M. Fenomenologia da percepção. Tradução Carlos Alberto de Moura. São Paulo: Martins Fontes, 1999.

MERLEAU-PONTY, M. Le visible et Vinvisible, Tradução Calude Lefort. Gallimard, 1964b. 
MERLEAU-PONTY, M. Notes de cours, 1959-1961. Editado: Stéphanie Ménasé. Paris: Gallimard, 1996, p. 219.

MERLEAU-PONTY, M. Sens et non-sens. Tradução Hubert L. Dreyfus e Patricia Allen Dreyfus. Paris, Nagel, 1964a.

MERLEAU-PONTY. L'Oeil et I'Esprit. Tradução James Edie. Paris: Gallimard, 1964.

NIETZSCHE, F. O livro do filósofo. In: Considerações Sobre o Conflito Entre a Arte e Conhecimento. Tradução Antônio Carlos Braga, Coleção Grandes Obras do Pensamento Universal - 76, São Paulo: Escala, 1872, p. 6-116. 